\title{
Intraplate and petit-spot volcanism originating from hydrous mantle transition zone
}

\author{
JIANGENG YANG', MANUELE FACCENDA' \\ 'Dipartimento di Geoscienze, Università di Padova, Italy \\ (manuele.faccenda@unipd.it)
}

Most magmatism occurring on Earth is conventionally attributed to passive mantle upwelling at mid-ocean ridges, slab devolatilization at subduction zones, and mantle plumes. However, the widespread Cenozoic intraplate volcanism in northeast China and the peculiar petit-spot volcanoes offshore the Japan trench cannot be readily associated with any of these mechanisms. Furthermore, the seismic tomography images show remarkable low velocity zones (LVZs) sit above and below the mantle transition zone which are coincidently corresponding to the volcanism. Here we show that most if not all the intraplate/petit-spot volcanism and LVZs present around the Japanese subduction zone can be explained by the Cenozoic interaction of the subducting Pacific slab with a hydrous transition zone. Numerical modelling results indicate that 0.2-0.3 wt. $\% \mathrm{H}_{2} \mathrm{O}$ dissolved in mantle minerals which are driven out from the transition zone in response to subduction and retreat of a stagnant plate is sufficient to reproduce the observations. This suggests that critical amounts of volatiles accumulated in the mantle transition zone due to past subduction episodes and/or delamination of volatile-rich lithosphere could generate abundant dynamics triggered by recent subduction event. This model is probably also applicable to the circum-Mediterranean and Turkish-Iranian Plateau regions characterized by intraplate/petit-spot volcanism and LVZs in the underlying mantle 